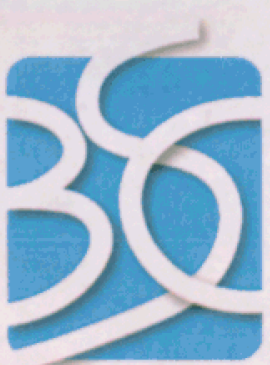

BECHTEL SAIC CONPANYLC

\title{
Electrical Support System Description Document
}

Prepared for:

U.S. Department of Energy

Office of Civilian Radioactive Waste Management

Office of Repository Development

1551 Hillshire Drive

Las Vegas, Nevada 89134-6321

Prepared by:

Bechtel SAIC Company, LLC

1180 Town Center Drive

Las Vegas, Nevada 89144

Under Contract Number

DE-AC28-01RW12101 


\section{QUALITY ASSURANCE}

The development of this document is not subject to the Quality Assurance Requirements and Description (DOE 2004) requirements. This document was developed in accordance with LP3.26Q-BSC, System Description Documents which is based on DOE-STD-3024-98, Content of System Design Descriptions.

\section{DISCLAIMER}

This report was prepared as an account of work sponsored by an agency of the United States Government. Neither the United States Government nor any agency thereof, nor any of their employees, nor any of their contractors, subcontractors or their employees, makes any warranty, express or implied, or assumes any legal liability or responsibility for the accuracy, completeness, or any third party's use or the results of such use of any information, apparatus, product, or process disclosed, or represents that its use would not infringe privately owned rights. Reference herein to any specific commercial product, process, or service by trade name, trademark, manufacturer, or otherwise, does not necessarily constitute or imply its endorsement, recommendation, or favoring by the United States Government or any agency thereof or its contractors or subcontractors. The views and opinions of authors expressed herein do not necessarily state or reflect those of the United States Government or any agency thereof. 



\begin{tabular}{c|c} 
System Description Document \\
Change History \\
Complete only applicable items
\end{tabular}

11. Page iv of 52

12. SDD Tite

Electrical Support System Design Description

13. Di

000-3YD-EU00-00100-000-003

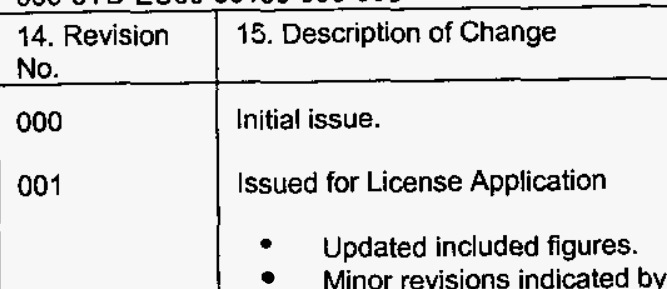

- Minor revisions indicated by change bars.

Updated DIRS report.

002

Rewrite to conform to the requirements of Rev 2 of LP-3.26Q-BSC

003

Complete revision due to requirements and formatting changes. 


\section{CONTENTS}

Page

FIGURES vi

ACRONYMS AND ABBREVIATIONS ix

1. INTRODUCTION

1.1 SYSTEM OR FACILITY IDENTIFICATION

1.2 LIMITATIONS OF THIS SYSTEM DESCRIPTION DOCUMENT

2. OVERVIEW

2.1 STRUCTURE, SYSTEM, OR COMPONENT FUNCTIONS.

2.2 STRUCTURE, SYSTEM, OR COMPONENT CLASSIFICATION .............................2-2

2.3 OPERATIONAL OVERVIEW

3. REQUIREMENTS AND BASES

3.1 GENERAL REQUIREMENTS

3.2 SPECIAL REQUIREMENTS AND BASES

3.3 ENGINEERING DESIGN REQUIREMENTS AND BASES

3.4 TESTING, AND MAINTENANCE REQUIREMENTS AND BASES

3.5 OTHER REQUIREMENTS AND BASES

4. SYSTEM DESCRIPTION

4.1 CONFIGURATION INFORMATION.

4.2 OPERATIONS

4.3 TESTING, AND MAINTENANCE

5. REFERENCES

5.1 DOCUMENTS CITED

5.2 CODES, STANDARDS, REGULATIONS, AND PROCEDURES

5.3 DATA TRACKING NUMBER ................................................................... 5-3

5.4 SOFTWARE CODES ..................................................................................

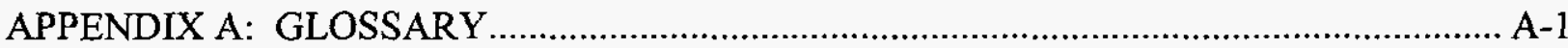

APPENDIX B: LIST OF KEY SYSTEM CHARTS, DIAGRAMS, DRAWINGS, \& LISTS

APPENDIX C: LIST OF SYSTEM PROCEDURES 
Electrical Support SDD

\section{FIGURES}

Page

2-1. Repository Grounding Requirements ........................................................... 2-5

2-2. Basic Cathodic Protection..................................................................................... 2-7 
Electrical Support SDD

INTENTIONALLY LEFT BLANK 


\section{ACRONYMS AND ABBREVIATIONS}

AC alternating current

ALARA as low as is reasonably achievable

AWG

American Wire Gauge

CCTV

DC closed circuit television

ETAP direct current

F\&OR

ITS Electrical Transient Analyzer Program

ITWI Functional and Operational Requirement

NEC important to safety important to waste isolation

PDC National Electrical Code

PRD Project Design Criteria

SDD

SNM

SSC Project Requirements Document

TBD System Description Document special nuclear material

TBV structure, system, or component

TSR UPS VAC to be determined to be verified Technical Safety Requirement uninterruptible power supply

VDC Volts - alternating current Volts - direct current 
Electrical Support SDD

INTENTIONALLY LEFT BLANK 


\section{INTRODUCTION}

The purpose of this revision of the System Design Description (SDD) is to establish requirements that drive the design of the electrical support system and their bases to allow the design effort to proceed to License Application. This SDD is a living document that will be revised at strategic points as the design matures over time. This SDD identifies the requirements and describes the system design as they exist at this time, with emphasis on those attributes of the design provided to meet the requirements. This SDD has been developed to be an engineering tool for design control. Accordingly, the primary audience/users are design engineers. This type of SDD both "leads" and "trails" the design process. It leads the design process with regard to the flow down of upper tier requirements onto the system. Knowledge of these requirements is essential in performing the design process. The SDD trails the design with regard to the description of the system. The description provided in the SDD is a reflection of the results of the design process to date.

Functional and operational requirements applicable to electrical support systems are obtained from the Project Functional and Operational Requirements (F\&OR) (Siddoway 2003). Other requirements to support the design process have been taken from higher-level requirements documents such as the Project Design Criteria Document (PDC) (Doraswamy 2004), and fire hazards analyses. The above-mentioned low-level documents address Project Requirements Document (PRD) (Canori and Leitner 2003) requirements.

This SDD contains several appendices that include supporting information. Appendix B lists key system charts, diagrams, drawings, and lists, and Appendix C includes a list of system procedures.

\subsection{SYSTEM OR FACILITY IDENTIFICATION}

The electrical support system supports the repository infrastructure by providing adequate and reliable electric support for construction and operation of all surface facilities and subsurface facilities. The electrical support systems for the emergency power system equipment will be seismically designed for the 1000-year earthquake. Acceptability of passive equipment such as cable trays and supports will be verified by analysis.

The electrical support system includes the following subsystems:

- Lighting

- Grounding

- Lightning protection

- Cathodic protection

- Heat tracing

- Cable raceway (including underground ducts) 


\subsubsection{Lighting}

The scope of the lighting subsystem is to provide and maintain highly reliable and adequate lighting for all areas of the repository facility, including subsurface lighting, to fulfill its functions per the requirements of the IESNA Lighting Handbook, Reference \& Application (Rea 2000), the National Electrical Code, (NFPA 70-2002) and IESNA Recommended Practice for Tunnel Lighting (ANSI/IESNA RP-22-96). The lighting requirements for the safeguards and security system are described in the Safeguard and Security SDD. Distribution voltage levels for the electrical system are described in the Electrical Power SDD. The lighting subsystem is divided into three subsystems: normal, essential, and emergency.

\section{Normal Lighting system:}

Normal lighting is provided in areas where sudden loss of light does not have any impact on either safety or production. Based on the power requirements, it is defined as a lighting system that receives 480/277 VAC (volts-alternating current) or 208/120 VAC power from the preferred $230 \mathrm{kV}$ utility power source, and backed by a $138 \mathrm{kV}$ alternate utility power source.

\section{Essential Lighting System:}

Essential lighting is provided in areas where long periods of loss of light have impact on production, or the safety to personnel. Based on the power requirements, it is defined as a lighting system that receives 480/277 VAC or 208/120 VAC power from the preferred $230 \mathrm{kV}$ utility power source, and backed by the following sources:

- Alternate $138 \mathrm{kV}$ utility power source

- $12.47 \mathrm{kV}$ standby diesel generators

\section{Emergency Lighting System:}

Emergency lighting system includes egress lighting system. Emergency lighting is provided in areas where emergency operations, control operations, sustained system operations and egress from the facility are required during emergency and off-normal events. Based on the power requirements, it is defined as a lighting system that receives 480/277 VAC or 208/120 VAC power from the preferred $230 \mathrm{kV}$ utility power source, and backed by the following sources:

- Alternate $138 \mathrm{kV}$ utility power source

- $4.16 \mathrm{kV}$ emergency diesel generators

- UPS system for the lighting area that cannot tolerate momentary loss of light.

Further, egress lighting is powered by self-contained dry battery packs/inverters within each fixture that turn light on upon loss of $120 \mathrm{VAC}$. Therefore, egress lighting is not connected to an emergency bus.

\subsubsection{Grounding}


The scope of the grounding subsystem is to:

- Protect personnel from electric shock hazards

- Protect equipment from excessive voltages

- Facilitate fault isolation

- Permit the dissipation of maximum ground fault currents

- Provide a stable reference point for instrumentation and control circuits.

The ground grid in the switchyard area is designed per the requirements of IEEE Standard 802000 to ensure that personnel and operating equipment are safe from harmful and destructive effects of high-ground potentials under all modes of repository operating conditions. This ground grid interfaces with the grounding of: subsurface facilities, power system, surge protection, instrument, equipment/raceway, facility/structure/lightning protection, railroad and fence. See Figure 2-1.

\subsubsection{Lightning Protection}

The scope of the lightning protection subsystem is to provide a designated low resistance path to the site grounding system for the lightning current per design requirements of NFPA Standard 780-2001, Standard for the Installation of Lightning Protection Systems, and UL 96A-2001, Installation Requirements for Lightning Protection Systems. The system neither attracts nor repels a lightning strike, but simply intercepts and guides the lightning current harmlessly to the ground. The lightning protection is provided to structures that project above surrounding parts such as building roofs, shaft houses, chimneys, ventilators, flagpoles, towers, antennas, water tanks, switchyard electrical equipment, and above ground storage/aging areas (i.e. surface aging areas).

\subsubsection{Cathodic Protection}

The scope of the cathodic protection subsystem is to control external corrosion on the metallic pipes, tanks and structures buried in, or in contact with the ground per the requirements of National Association of Corrosion Engineers (NACE) Standard RP0169-2002.

\subsubsection{Heat Tracing}

The scope of the electric heat tracing subsystem is to provide freeze protection for liquid filled piping, instrument sensing lines, and tanks that are susceptible to freezing per the requirements of IEEE Std. 515-1997 and NFPA 70-2002. The electric heat tracing subsystem uses a self-limiting heating cable, or electrical heating element, around the pipe or sensing line to keep the liquid above its freezing point. The electrical supply for the heat tracing subsystem is $208 / 120 \mathrm{VAC}, 3-$ phase, 4-wire service.

\subsubsection{Cable Raceway}


The scope of the cable raceway subsystem is to provide a highly reliable cable raceway system to fulfill its functions per the requirements of NFPA 70-2002. The cable raceway subsystem is primarily used to provide physical protection and routing of electrical power, control, and instrument cables from the power supply to the electrical loads and of cables interconnecting control and monitoring equipment. The cable raceway subsystem is comprised of metallic or nonmetallic conduits, enclosed or open cable trays, electrical boxes, and the underground electrical duct bank system, including manholes and handholes. The cable tray system and conduits are used for the surface and subsurface facilities power. The power distribution from the switchyard and switchgear facility is in underground concrete duct banks utilizing nonmetallic conduits. The cable raceway subsystem interfaces with the following surface and subsurface systems: electrical power systems, electrical equipment, instrument, control systems, communication system, lighting subsystem, grounding subsystem, lightning protection subsystem, heat tracing subsystem and cathodic protection subsystem.

\subsection{LIMITATIONS OF THIS SYSTEM DESCRIPTION DOCUMENT}

As noted above, the electrical support system interfaces with the Electrical Power System that is described in a separate SDD. This SDD may include assumptions, preliminary information, and to be verified (TBV) values, as appropriate to the current level of design development. Additionally, requirements or descriptions that are stated as to be determined (TBD) or are expected at a later phase of the design will be described as such. At the time of approval of this version, the status of the design is that the conceptual design has been completed and the Title I preliminary design has been started. As the necessary design documents (calculations, drawings, specifications, and other supporting documents) are completed, the description of the system design will be updated.

\subsection{OWNERSHIP OF THIS SYSTEM DESIGN DOCUMENT}

The electrical support system SDD is owned by the Electrical and Control Systems group of Design and Engineering. 


\section{OVERVIEW}

\subsection{STRUCTURE, SYSTEM, OR COMPONENT FUNCTIONS}

The electrical support system is described as follows in F\&OR Section 1.4.1.2-3 (Siddoway 2003):

"The repository shall provide the support system to maintain electrical power.

The repository shall provide electrical support system such as: a. Lighting,

b. Grounding, .c. Lightning Protection, d. Cathodic Protection, e. Heat Tracing, f.

Cable Raceway"

System functional requirements from the F\&OR (Siddoway 2003) are contained in the subsection titles. The implementing performance/operational requirements are described in each subsection along with the requirement number of the F\&OR (Siddoway 2003).

\subsubsection{Lighting}

2.1.1.1 The function of lighting is to provide the adequate level of illumination for (but not limited to): personnel safety, task lighting, yard/outdoor activities, daily activities within buildings, process areas, closed circuit television (CCTV) operations, and maintenance of repository (F\&OR 1.4.1.2-3a, Siddoway 2003). Further, based on the lighting requirements during different operating modes, the lighting subsystem is divided into three subsystems: normal, essential, and emergency lighting subsystems as shown in the following.

Normal Lighting: The function of the normal lighting system is to provide adequate level of illumination during normal operating mode.

Essential Lighting: The function of the essential lighting system is to provide adequate level of illumination during total loss of off-site power sources (utility sources) by utilizing standby diesel generators.

Emergency Lighting: The function of the emergency lighting system is to provide adequate level of illumination for the emergency functions during an off-normal event, or total loss of off-site power sources by utilizing emergency power sources.

\subsubsection{Grounding}

2.1.2.1 The grounding subsystem has the following functions (F\&OR 1.4.1.2-3b, Siddoway 2003):

To assure that persons in the vicinity of grounded facilities are not exposed to the danger of critical electric shock under normal, and ground fault conditions.

To provide means to carry maximum system ground fault, and lightning current to ground, thereby allowing protection systems to isolate faulted systems, protecting equipment from 
malfunction, and damage due to excessive voltages, and protecting the building/structure from lightning strikes.

To provide a stable reference point for computer systems, test equipment, instrument, and control circuits.

\subsubsection{Lightning Protection}

2.1.3.1 The function of the lightning protection subsystem is to provide a designated low resistance ground path for the lightning current to protect life, electrical equipment, buildings, and elevated structures against damages caused by lightning strikes (F\&OR 1.4.1.2-3c, Siddoway 2003):

\subsubsection{Cathodic Protection}

2.1.4.1 The function of the cathodic protection subsystem is to inhibit corrosion of buried structures, such as underground pipes, tanks, etc. (F\&OR 1.4.1.2-3d, Siddoway 2003):

\subsubsection{Heat Tracing}

2.1.5.1 The function of the electrical heat tracing subsystem is to provide freeze protection for liquid-filled piping, instrument sensing lines, and tanks that are susceptible to freezing during the winter months (F\&OR 1.4.1.2-3e, Siddoway 2003):

\subsubsection{Cable Raceway}

2.1.6.1 The function of the cable raceway subsystem is to provide physical support, and protection for electrical cables routed in the facility (F\&OR 1.4.1.2-3f, Siddoway 2003):

\subsection{STRUCTURE, SYSTEM, OR COMPONENT CLASSIFICATION}

The electrical support system has been categorized as a non-safety-category (non-SC) SSC. This system consists of no SSCs important to safety (ITS) or natural, and engineered barriers that are important to waste isolation (ITWI). This system is in the non-SC.

Additional information regarding system classification maybe found in Q-List (BSC 2003 [DIRS 165179]), Safety Classification of SSCs, and Barriers (BSC 2004 [DIRS 169971]), and Preliminary Nuclear Safety Design Bases for License Application (BSC 2003 [DIRS 165182]).

\subsection{OPERATIONAL OVERVIEW}

\subsubsection{Lighting Subsystem Operational Overview}

The lighting subsystem for the repository is subdivided into normal lighting, essential lighting, and emergency lighting. 
The normal lighting system serves the general outside facility areas, roadways, parking lots, building offices, and other areas where loss of power does not have any impact on safety or production. Therefore, normal lighting system is powered from either utility sources, $230 \mathrm{kV}$, preferred source or $138 \mathrm{kV}$, alternative source, only. As a result, the loss of two utility sources will cause the normal lighting system to be out of service.

The essential lighting system serves the process facilities, and areas that require lighting to prevent production loss, maintain normal operation or to achieve sustained system operations during loss of offsite power. Therefore, the essential lighting system is powered from either utility sources, $230 \mathrm{kV}$, preferred source or $138 \mathrm{kV}$, alternative source, and backed by standby diesel generators. This configuration allows essential lighting to be available upon loss of both utility sources.

Emergency lighting system includes egress lighting system. Emergency lighting is provided in areas where illumination is required for emergency operations, and egress from the facility. Therefore, the emergency lighting system is powered from utility sources, $230 \mathrm{kV}$, preferred source or $138 \mathrm{kV}$, alternate source, and backed by emergency diesel generators, and a UPS system. Egress lighting provided in exit areas is further powered by self-contained dry battery packs/inverters within each fixture, which turns on upon loss of $120 \mathrm{VAC}$. Therefore, egress lighting is not connected to emergency bus. The UPS system provides power for lighting in $\mathrm{CCCF}$, and local control areas inside the facilities, critical closed circuit television (CCTV) area, switchyard, and main switchgear buildings, and radiation monitoring system that are needed during emergency operating conditions. This configuration provides maximum reliability for power supplied to the emergency lighting system.

Please note that power backed by the diesel generator will result in momentary loss of light in the area. Therefore, if the area lighting cannot tolerate the momentary loss of light, then the UPS shall back the area lighting.

\subsubsection{Grounding Subsystem Operational Overview}

The ground grid system, and its extension to overall site grounding conductors reduce the intolerable levels of touch, and step potentials to safe tolerable levels of potentials during ground fault, and normal operating conditions, and thereby ensure that personnel, and operating equipment are safe from harmful, and destructive effects of high-ground potentials. The electrical system is grounded to limit transient over-voltages during a phase-to-ground short circuit, and provides a ground current return path to isolate faulted circuits.

The equipment grounding system interconnects the non-current-carrying parts of all electrical equipment, and adjacent conductive material with the earth, and circuit neutrals. See Figure 2-1. Equipment is grounded for the following reasons:

- To protect personnel from electric shocks

- To prevent damage to equipment 
The instrument/computer grounding, although it also connects to the overall grounding subsystem, is kept separate, and insulated, until it connects to the grounding subsystem at one specific point to eliminate electrical noise problems on the power supply lines for instrument, and monitoring equipment, see Figure 2-1. 


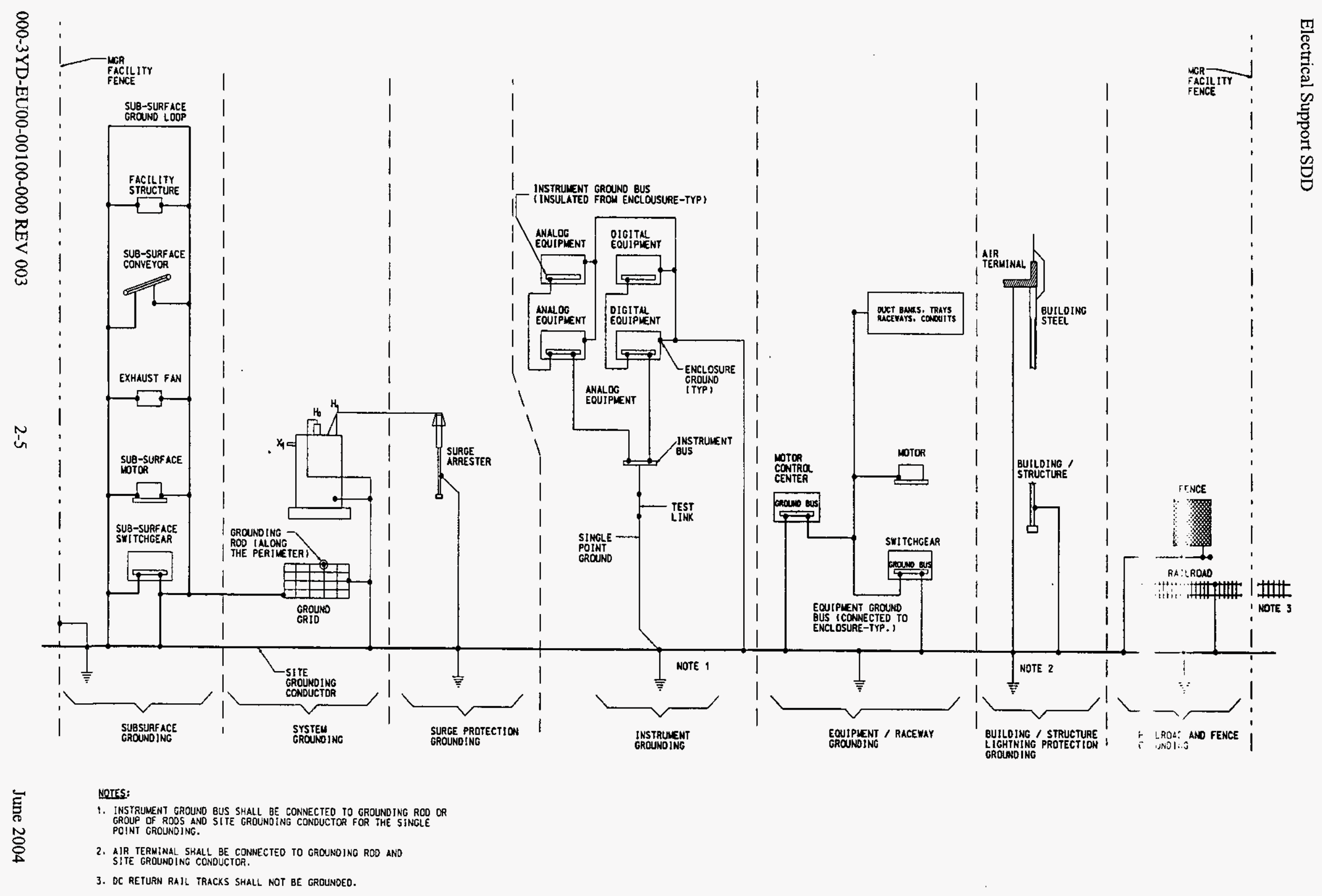

Figure 2-1 Repository Grounding Requirements 


\subsubsection{Lightning Protection Subsystem Operational Overview}

Lightning current discharge through a higher resistance path to the ground can cause damage to surrounding areas and life due to the heat and mechanical forces generated during the passage of the lightning current discharge. Electrical conductors are virtually unaffected by either the heat or the mechanical forces when adequately sized to carry the expected current. Therefore, lightning protection is provided to buildings, and other outdoor elevated structures by installing air terminals or vertical lightning rods on top of the structures, and connecting them to the site grounding rods that are connected to the ground grid. The air terminals on top of the building are interconnected in a network pattern, and are connected down to the ground rods with a minimum of two down conductors. The lightning rods intercept the lightning strikes, and provide a designated path for the lightning current to dissipate to the ground grid, and thereby protect electrical equipment, buildings, and elevated structures against damages caused by lightning strikes, see Figure 2-1.

\subsubsection{Cathodic Protection Subsystem Operational Overview}

Cathodic protection is an effective electrical method of corrosion control on metallic structures exposed to an electrolyte, namely soils, and liquids. The system consists of components such as rectifiers, anodes, anode loop cables, terminal, and junction boxes, test stations, reference electrodes, and some bonding jumpers. See Figure 2-2.

This system uses the direct current (DC) from the rectifiers powered at $480 \mathrm{VAC}$ or $120 \mathrm{VAC}$. Corrosion protection is accomplished by forcing the metallic structure to act as a cathode. In this system of protection, positive $(+)$ output of the rectifier is connected to the anode material where corrosion occurs, then the flow of current goes to the pipeline or metallic structure, and back to the negative terminal of the rectifier. The rectifier has adjustable voltage taps for adjustment to meet the required negative potential relative to a reference electrode. The potential requirement for corrosion control at structure is a negative between the structure, and a saturated coppercopper sulfate reference electrode in contact with the electrolyte. 
Impressed Current System

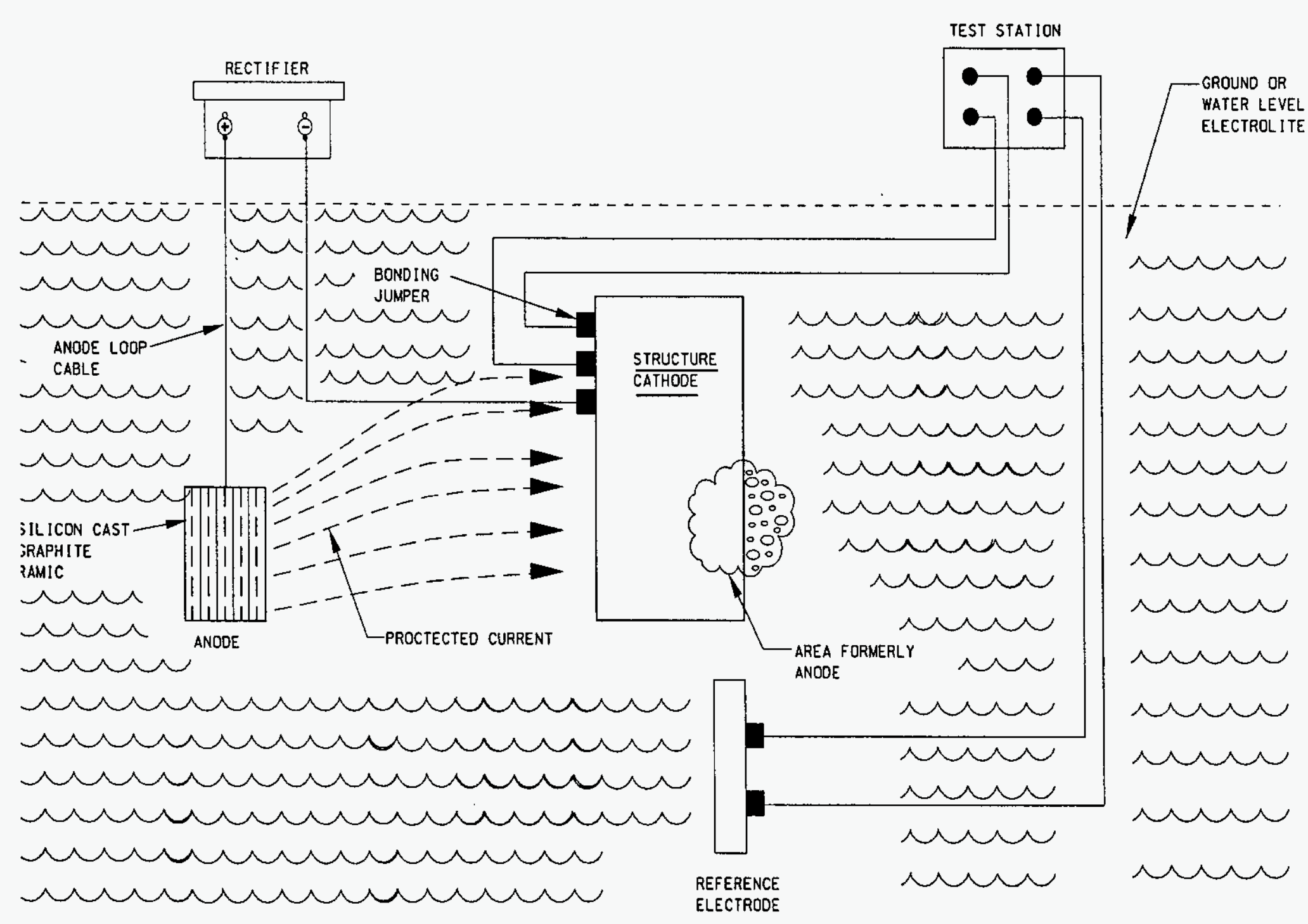




\subsubsection{Heat Tracing Operational Overview}

The heat trace system is provided to outdoor pipes, instrument sense lines, and tanks that contain liquids to keep these liquids above their freezing points. The system consists of heating elements, temperature sensing units, temperature controllers, system monitors, and an electrical power supply at 208/120 VAC, 3-phase, 4-wire service.

Two types of heating elements are used: heat tracing cable elements used for pipes, and small tanks, and heater pads used for large tanks. Heat tracing cable is self-limiting, which means that the amount of heating current that the cable generates is dependent on the ambient temperature. Please note that the high temperature fluid systems, if any, may require the use of mineral insulated heat cable. The heater cables are secured to the pipes with polyester fiber or glass cloth adhesives.

The heat tracing circuitry is divided into zones, and protected by separate circuit breakers for system isolation. The heat tracing subsystem monitors provide status, alarms locally at the panel, and remotely at the Central Control Center Facility (CCCF) to indicate normal circuit operation or sensing of off-normal conditions such as circuit power failure or loss of circuit continuity.

\subsubsection{Cable Raceway Subsystem Operational Overview}

The cable raceway subsystem operates as a passive system. It is primarily used to provide physical protection, and routing of electrical power, and instrument cables routed from the power supply to the electrical loads, and of cables interconnecting control, and monitoring equipment. The system consists of metallic or nonmetallic conduits, enclosed or open cable trays, boxes, and underground concrete duct banks. Cable raceways are separated in accordance with the cable voltage levels, the cable functions by quality level, process requirements of redundancy, and cable routing in accordance with fire protection criteria. The exposed raceway system utilizes cable trays, and conduits, neatly arranged in a main distribution pattern, branching out to their individual loads, and equipment. The embedded raceway system consists of conduits embedded in building floors, walls, and in underground duct banks. The power from the switchyard is distributed to facilities by underground concrete duct banks, and overhead distribution lines. 


\section{REQUIREMENTS AND BASES}

All requirements referencing Preliminary Nuclear Safety Design Bases for License Application (BSC 2003 [DIRS 165182]) are classified as 10 CFR Part 63 requirements, and are located in Section 3.1.1.1. The remaining requirements, and associated bases are classified as External Compliance unless noted within the appropriate comment section.

\subsection{GENERAL REQUIREMENTS}

\subsubsection{System Functional Requirements}

\subsubsection{Safety Requirements}

Safety requirements in Section 3.1.1.1 are nuclear design bases from the Preclosure Safety Analysis. Other requirements that address safety issues such as personnel protection from process industrial hazards or nuclear criticality safety requirements are contained in the Special Requirements section or other topical section below.

\subsubsection{Environmental Requirements}

Specific environmental requirements for the facility have not been identified at this stage of the design. Environmental requirements for addressing land disturbance from facility construction, facility emissions, water use or pollution prevention requirements may be needed, and will be added to the SDD when these requirements are developed. See Sections 3.2.7.1, and 3.5.5.1 for additional Environmental Protection Program Requirements.

\subsubsection{Mission-Critical Requirements}

The electrical support system includes the following subsystems:

- Lighting

- Grounding

- Lightning protection

- Cathodic protection

- Heat tracing

- Cable raceway (including underground ducts).

\subsection{Lighting}

3.1.1.3.1.1 Requirements: The lighting subsystem shall consist of the normal, essential, and emergency lighting systems. The normal lighting shall be provided in areas where sudden loss of light does not have any impact on either safety or production. The essential lighting shall be provided in areas where sudden loss of light does have impact on production, and safety to personnel. Emergency lighting shall be provided in areas where manual operations, sustained system operations, and egress from the facilities are required during postulated emergencies. Supports Function 2.1.1. 
Basis: Based on the functional requirements, lighting subsystem is divided into three subsystems to provide reliable lighting during all modes of facilities operations [PDC 4.3.1.2.1].

3.1.1.3.1.2 Requirement: As a minimum, the lighting subsystem shall provide the illumination levels per the requirements of Illuminating Engineering Society of Northern America (IESNA) Lighting Handbook, Reference, and Application, $9^{\text {th }}$ edition (2000), ANSI/IESNA standard RP-22-96, NFPA 70-2002.

Basis: This requirement will ensure adequate illumination for all areas in the facility, and operations during all modes of facilities operations [PDC 4.3.1.2.2].

\subsection{Grounding}

3.1.1.3.2.1 Requirement: The ground grid shall be provided to protect the safety of site personnel, and the general public, systems, structures, buildings, and components during a system fault (short circuit), a lightning strike, or a system voltage surge. The ground grid shall be designed per the requirements of IEEE Std. 80-2000 to limit touch, and step potentials to safe under all ground fault conditions. The ground soil resistivity shall be measured per the requirements of IEEE Std. 81-1983. Supports Function 2.1.2.

Basis: This requirement will provide adequate protection of site personnel, and the general public, systems, structures, buildings, and components during a system fault (short circuit), a lightning strike, or a system voltage surge in accordance with IEEE Std. 80-2000, IEEE Std. 142-1991, and IEEE Std. 81-1983 [PDC 4.3.1.4.3].

3.1.1.3.2.2 Requirement: The ground grid conductor, and grounding conductor shall be made of bare copper and shall be buried below the earth surface at no less than two, and a half feet deep. The grounding rods shall be of copper clad steel. Supports Function 2.1.2.

Basis: The copper clad steel ground rods can be driven through the hard soil without damage. This rationale is based on the IEEE Std. 80-2000. The second rationale to install ground conductor below the earth surface at no less than two, and a half feet deep is based on the NFPA 70-2002 [PDC 4.3.1.4.4].

3.1.1.3.2.3 Requirement: Electrical equipment, buildings steel structures, fence, and metal components shall be effectively grounded to the ground grid per the requirement of IEEE Std.142-1991 and NFPA 70-2002. Supports Function 2.1.2.

Basis: Electrical equipment, buildings steel, and metal structures shall be effectively grounded for personnel safety, and protection of equipment, buildings, and structures. This rationale is based on the recommendations of IEEE Std. 142-1991, and NFPA 70-2002 [PDC 4.3.1.4.5].

3.1.1.3.2.4 Requirement: The grounding conductor for the instrument, digital systems, communication systems, and computer systems shall be kept separate, and insulated until it connects to the grounding subsystem at one specific point. Supports Function 2.1.2

Basis: This requirement will mitigate electrical noise problems in computer systems, test equipment, instrument, and control circuits to prevent system malfunctions due to electrical noise on the line. This rationale is based on the recommendations of IEEE Std. 142-1991[PDC 4.3.1.4.6].

\subsection{Lightning Protection}


3.1.1.3.3.1 Requirement: All buildings, outdoor elevated structures; electrical equipment, and electrical power transformers shall be protected with lightning arresters, and surge capacitors against damages caused by lightning strikes. Lightning protection subsystem shall be installed for all buildings, and outdoor elevated structures in accordance with the NFPA 780-2001, and UL 96A-2001 standards. Supports Function 2.1.3.

Basis: Lightning protection is required to provide a designated low resistance path for the lighting current to dissipate to the ground harmlessly, and thereby protect life, equipment, buildings, and elevated outdoor structures against damages caused by lightning strikes [PDC 4.3.1.5.1 and PDC 4.3.1.5.2].

\subsection{Cathodic Protection}

3.1.1.3.4.1 Requirement: Cathodic protection subsystem shall be provided to mitigate underground metal corrosion for the underground metal piping systems, and tanks in contact with soil. Cathodic protection subsystem shall be designed per the requirements of NACE Std. RP0169-2002. Supports Function 2.1.4.

Basis: Cathodic protection subsystem mitigates corrosion, and thereby increases the useful life of the existing underground metal piping systems, and tanks in contact with soil. Cathodic protection subsystem also prevents the premature failures of the underground metal piping systems, and tanks in contact with soil [PDC 4.3.1.6.1].

\subsection{Heat Tracing}

3.1.1.3.5.1 Requirement: Electrical heat tracing subsystem (freeze protection) is required for the liquid-filled piping, and instrumentation sensing lines that are subject to freezing to support continuous operation of liquid-filled piping, and instrumentation sensing lines. Electrical heat tracing (freeze protection) shall be provided per the requirements of the IEEE 515-1997. The system shall be operable for the outdoor temperature range as defined in PDC, section 6.1.1.5. The turn on, and turn off temperature settings of the heat tracing subsystem shall be based on the fluid properties, and characteristics of the pipe insulation. Supports Function 2.1.5.

Basis: Electrical heat tracing subsystem (freeze protection) is needed for the continuous operation of liquid-filled piping, and instrumentation sensing lines [PDC 4.3.1.7.1].

3.1.1.3.5.2 Requirement: In heat tracing circuit, ground leakage protection shall be employed, and configured to provide both local, and remote indication of a ground fault. Supports Function 2.1.5.

Basis: This is required for the safe operation of the heat tracing circuit by detecting ground leaks early. Timely detection prevents propagation to larger faults. This requirement is based on the common industry practice [PDC 4.3.1.7.4].

\subsection{Cable Raceway}

3.1.1.3.6.1 Requirement: Depending on ways of exposure, raceways shall be divided into two major classes, exposed systems, and embedded systems. Exposed systems shall utilize cable tray 
or conduit, arranged in a main distribution pattern branching out to serve individual equipment or devices. Embedded systems shall consist of conduit embedded in building floors (including trench), walls, and in underground duct banks. In-floor trenches and cable pits can be used as required in special cases. The cable raceway for 600 volts nominal or less shall be designed per the requirements of NFPA 70-2002, Chapter 3, and PDC. The cable raceway for the medium voltage system shall be designed by using PDC, industry standards such as IEEE, NEMA, and other applicable industry standards. Supports Function 2.1.6.

Basis: The cable raceway shall be designed to provide adequate mechanical protection for cables, personnel safety, and safe facility operations. This is a common practice in industry [PDC 4.3.1.8.2.1].

3.1.1.3.6.2 Requirement: Only metallic type cable trays shall be used. Instrumentation trays shall have solid bottoms, and covers. Supports Function 2.1.6.

Basis: The metallic type cable trays are selected for grounding cable trays. This is a common practice in industry [PDC 4.3.1.8.2.5].

3.1.1.3.6.3 Requirement: For the selected critical emergency redundant loads " $A$ ", and " $B$ ", cable raceway shall be separated, and routed from the emergency power systems $A$, and $B$ via separate fire zones in accordance with the principles defined in NFPA 70-2002, Article 700.9. Supports Function 2.1.6.

Basis: The electrical support is a non-ITS system. However, for the selected emergency redundant loads, physical separation of emergency power cables are required to prevent simultaneous loss of selected emergency loads due to a fire in the same fire zone or other hazards such as flooding, icing, and vandalism [PDC 4.3.1.8.1].

\subsubsection{General Requirements}

\subsection{Heat Tracing}

3.1.1.4.1.1 Requirement: The heat tracing cable supply voltage shall be $120 \mathrm{VAC}, 60 \mathrm{~Hz}$. The incoming power at the primary side of power distribution transformer for the heat tracing subsystem shall be 480 VAC, 3-phase, $60 \mathrm{~Hz}$. Supports Function 2.1.5.

Basis: The $120 \mathrm{VAC}$, and $208 \mathrm{VAC}$ are the most commonly accepted input voltage levels for the heat tracing subsystem in the industry [PDC 4.3.1.7.2].

3.1.1.4.1.2 Requirement: The normal power shall be used to supply power to the heat tracing subsystem. Backup standby and emergency diesel generator power sources shall not be used to supply power to the heat tracing subsystern unless it is required for some specific process to support emergency operations in freezing weather. Supports Function 2.1.5.

Basis: This requirement will reduce load on the diesel generators during power outages or emergency as loss of power to the heat tracing subsystem génerally will not have any impact either on the operations or on the safety [PDC 4.3.1.7.3].

\subsection{Cable Raceway}


3.1.1.4. 2 Requirement: Tray lengths shall be provided as necessary to fit the design situation with the tray widths, and heights as listed below: Supports Function 2.1.6.

- 12 in. wide by 4 in. high

- 18 in. wide by 4 in. high

- 24 in. wide by 4 in. high

- 30 in. wide by 4 in. high

- 36 in. wide by 4 in. high.

Basis: The cable tray sizes are selected to standardize cable tray types [PDC 4.3.1.8.2.5].

3.1.1.4.2.2 Requirement: In general, for areas using vertically stacked trays, the highest voltage cables shall occupy the highest position in the stack. Low voltage power cables in vertically stacked trays shall be located below medium voltage power cables. Control cables shall be located below low voltage power trays, and low voltage analog, and digital communication cables or fiber optic cables located below control cable trays. Tray systems for each voltage level application are installed from top to bottom order as shown in the following:

- $15 \mathrm{kV}$ cables

- $5 \mathrm{kV}$ cables

- Low voltage power AC, and DC-600 V cables

- High-level control signal or discrete on/off control cables (120 VAC, 125 VDC)

- Instrumentation cables (that is, low-level analog, and digital signal.)

- Communications cables.

Basis: This is required because the higher voltage cables are more prone to start a fire. In case of a fire, generated heat will flow above. This practice will prevent damaging lower voltage cables in case of fire generated in higher voltage cable trays. This is a common practice in industry [PDC 4.3.1.8.2.7].

3.1.1.4.2.3 Requirement: Cables shall be routed in conduit, or in cable trays with conduit dropouts to the individual equipment, and devices. Underground duct banks shall be used between facilities, and outlying structures. Supports Function 2.1.6.

Basis: This is a common practice in industry for the physical support, and protection of cables. The duct bank prevents exposure of cable routing in the open areas of the surface facility [PDC 4.3.1.8.2.2].

3.1.1.4. 2.4 Requirement: Power cable connections to loads in remote areas through rough mountainous surfaces shall be by overhead lines. Supports Function 2.1.6.

Basis: This is required where the land is mountainous, and duct bank installation is not practical, or where distance involved cannot justify the high duct bank cost. Therefore, the overhead distribution lines are used for remote loads only when underground distribution is not a viable solution or it is too costly to implement [PDC 4.3.1.8.2.3].

3.1.1.4.2.5 Requirement: A raceway designated for a single class of cables shall contain only cables of the same class. Cable trays containing low voltage instrumentation cables with very low current control signals shall provide protection against spurious signal sources. During fiber optic cable tray design, the minimum bend radius of fiber optic cable shall be taken into account. Supports Function 2.1.6. 
Basis: This criterion is required to prevent signal, and noise interference between different classes of cables. This is a common practice in industry. Protection of instrumentation cables is for prevention of equipment malfunctions due to noises mixed with normal signals [PDC 4.3.1.8.2.4].

3.1.1.4.2.6 Requirement: Cable rated at $300 \mathrm{~V}$ may be routed in the same raceway as $600 \mathrm{~V}$ cable, and share the same enclosures (boxes), provided the maximum applied voltage of the 600 $\mathrm{V}$ cable does not exceed $300 \mathrm{~V}$. Supports Function 2.1.6.

Basis: This is required to prevent the mixing of $120 \mathrm{~V}$ low power or control circuit cables rated $300 \mathrm{~V}$ or below with $600 \mathrm{~V}$ class power cables normally carrying a higher amount of power at $480 \mathrm{~V}$. This is a common practice in industry to achieve a reliable power system [PDC 4.3.1.8.2.8].

3.1.1.4.7 Requirement: Conduit for power, lighting, instrumentation, and all indoor exposed conduit shall be rigid, galvanized steel. Lighting subsystem may use electrical metal tubing for concealed work in non-hazardous areas, such as offices, and control rooms. Generally, PVC conduits shall be used for underground duct banks, except PVC-coated rigid, galvanized steel shall be used under heavy traffic areas. The minimum bend radius of fiber optic cable shall be reviewed during conduit design. Supports Function 2.1.6.

Basis: This is a common practice in industry for a reliable, and long lasting raceway installation [PDC 4.3.1.8.2.9].

3.1.1.4.2.8 Requirement: For underground installation, concrete encased underground duct banks, and manhole systems shall be installed throughout the site for the pulling, and protection of power, control, and instrumentation cables. Twenty percent conduit spare capacity shall be provided for underground duct banks. Supports Function 2.1.6.

Basis: This criterion is used to facilitate the cable routing between buildings or facilities. This is a common practice in industry for a reliable power distribution system. [PDC 4.3.1.9.1].

3.1.1.4.2.9 Requirement: Manholes, and pull points shall be used as required to facilitate cable pulling, and inspection. Their sizes, and locations shall depend on associated duct banks, type, and sizes of the cables to be installed, and shall be shown on the layout drawings. The maximum distance between manholes, and pull points shall be as allowed by the National Electric Code (NEC). Manholes, and pull points shall be provided with appropriate drainage. Copper grounding pad shall be provided in each manholes. Supports Function 2.1.6.

Basis: This is required to facilitate cable pulling activities. Grounding requirement is for the protection of personnel, and equipment against electric hazard. This is a common practice in industry for a reliable manhole installation [PDC 4.3.1.9.3].

\subsubsection{Subsystem, and Major Components}

The electrical support system is a title, and therefore, does not have any subsystems. Six systems are grouped together under the title of electrical support system, and each one of the system has its own specific function in ensuring the availability of the electrical power at all times for the repository. Therefore, these systems are described under Section 4.1.1, "Description of System, Subsystems, and Major Components". 


\subsubsection{Boundaries, and Interfaces}

The electrical support system interfaces with:

All facilities, and their housed systems to provide support for the electrical power

- The underground metal piping systems, and tanks in contact with soil for cathodic protection

- The liquid-filled piping, and instrumentation sensing lines that are subject to freezing.

The electrical support system interfaces with the electrical power system. This latter system provides requirements for normal power, standby power, and emergency power. There are no other system boundary requirements that must be accounted for in the design of the system.

\subsubsection{Codes, Standards, and Regulations}

Codes, standards, and regulations that apply to the electrical power system are contained in the PDC (Doraswamy 2004) in the following sections:

- Section 4.3.1 - general design criteria

- Section 4.3.6 - electrical support system: codes and standards.

\subsubsection{Operability}

The electrical support system is non-SC, and therefore is not subject to Technical Safety Requirements. Therefore there are no operability requirements for the system.

\subsection{SPECIAL REQUIREMENTS AND BASES}

Hazards Analyses are not yet complete, but are assumed to be potentially applicable. This section will be updated for each hazard with information on applicability/non-applicability, mitigating, and fail-safe performance requirements, environments, monitoring, alarms, and interfaces. See the Preliminary Hazards Analysis for License Application, (BSC 2004 [DIRS 167313]) for additional information.

\subsubsection{Radiation, and Other Hazards}

3.2.1.1 Requirement: The electrical support system components shall be hardened or properly shielded to withstand, and operate under the radiation levels in which they are installed commensurate with the performance basis of the equipment.

Basis: The requirement ensures that the system components will perform their intended functions. [PDC 4.9.3.5].

\subsubsection{As Low as is Reasonably Achievable}


3.2.2.1 Requirement: The electrical support system components shall be located, and/or shielded to minimize exposure to meet as low as is reasonably achievable (ALARA) principles.

Basis: This requirement will minimize personnel exposure. [PDC 4.9.3.3].1

\subsubsection{Nuclear Criticality Safety}

3.2.3.1 Requirement: The electrical support system shall be designed so that it does not initiate a credible criticality event.

Basis: Nuclear facility safety standards seek to prevent unplanned nuclear criticality events, and protect workers, and environment from potentially harmful exposures. This requirement will ensure that the above goal is met. [PDC 4.9.2.2.1]

\subsubsection{Industrial Hazards}

There are no requirements currently identified to address industrial hazards in the design of this system. As the design matures, requirements for addressing industrial hazards will be established as needed.

\subsubsection{Operating Environment, and Natural Phenomena}

\subsubsection{Normal Environment}

The requirements for the normal environment are addressed in PDC section 6.1.1.

\subsubsection{Earthquake}

3.2.5.2.1 Requirement: The electrical support systems for the emergency power system equipment shall be seismically designed for the 1000-year earthquake. Acceptability of passive equipment such as cable trays, and supports will be verified by analysis.

Basis: This requirement is to ensure that the electrical support systems for the emergency electrical power system are available after a seismic event. (Preliminary Hazards Analysis for License Application. [BSC 2004, DIRS 167313])

\subsubsection{Tornado, Extreme Winds, Rainstorm}

3.2.5.3.1 Requirement: The electrical support systems for the emergency electrical power system shall include provisions that assure that system will be functional under conditions such as high winds, rainstorm, or tomadoes.

Basis: This requirement is based on good engineering practice, and operational experience.

\subsubsection{Flooding}

3.2.5.4 Requirement: The electrical support system component shall be installed in a manner that will prevent any impact due to flooding. 
Basis: This requirement is necessary to prevent power outages, and damages to electrical power system due to flooding.

\subsubsection{Human Interface Requirements}

The electrical support system is non-SC, and therefore does not require any alarms, indicators or controls for manual safety functions. Therefore there are no human interface requirements for the system design currently needed. As system design evolves and system operations documents are developed, design requirements to assure appropriate human interface with the system may be needed.

\subsubsection{Specific Commitments}

3.2.7.1 Requirement: The repository shall be designed with pollution prevention systems to control air emissions, and effluents, minimize water use, and reduce or eliminate discharges to the environment.

Basis: The design shall comply with applicable environmental requirements set forth by federal and state regulations, Executive Orders, and DOE Directives, and requirements derived from environmental permits and corresponding permit conditions. [PDC 4.1.1.9]

\subsection{ENGINEERING DESIGN REQUIREMENTS AND BASES}

\subsubsection{Civil, and Structural}

See Section 3.2.5.2.1, Earthquake

3.3.1.1 Requirement: All support for the electrical duct banks shall be designed per the requirement of PDC Section 4.2.1.3.9.

Basis: This criterion is required to protect the integrity of electrical duct bank installation.

\subsubsection{Mechanical, and Materials}

The electrical support system is comprised of standard, commercial grade components, and no special design requirements are needed for mechanical or material engineering of the system.

\subsubsection{Chemical, and Process}

There are no chemical, and process requirements for the design of the electrical support system.

\subsubsection{Electrical Power}

3.3.4.1 Requirement: The following subsystems of the electrical support system will need AC power as shown below:

- Lighting subsystem - 480/277 VAC or 208/120 VAC, 3-phase, 4-wire service required from the preferred $230 \mathrm{kV}$ off-site source, backed by a $138 \mathrm{kV}$ off-site alternate utility 
power source, standby, and emergency diesel generators, and a non-emergency, and emergency UPS system.

- Cathodic Protection - Powered from normal power source, 480 VAC or 120 VAC.

- Heat Tracing - Powered from normal power source, 208/120 VAC, 3-phase, 4-wire service.

Basis: This requirement is based on good engineering practice.

\subsubsection{Instrumentation, and Control}

The detailed information for instrumentation, and engineering control requirements for the electric support systems will be updated in future revisions as the design evolves.

\subsubsection{Computer Hardware, and Software}

There is no computer hardware, and software requirements currently established for the electrical support system. As the repository design matures, the engineering requirements for the computer hardware, and software systems will be developed for this section. At present, engineering is planning to use the following computer programs per BSC requirements:

- Bechtel Corporation SETROUTE program for the cable raceway subsystem

- SETROUTE program is capable of linking equipment, raceway, and cable. It is also capable of providing a qualified database that may be used to route cable, track inventory of equipment, cable, and raceway. This program is used to develop cable pull tickets, and for the design, and installation of the cable raceway subsystem.

- ETAP, PowerStation for the design of ground grid.

\subsubsection{Fire Protection}

Fire protection requirements for the design of the system are tied to the facility that houses the system's components and brush clearance requirements for duct banks that are not in facilities, or overhead lines. These requirements are found in Site Fire Hazards Analyses (BSC 2004 [DIRS 168149]), and Subsurface Repository Fire Hazards Analysis (BSC 2004 [DIRS 168726]).

\subsection{TESTING, AND MAINTENANCE REQUIREMENTS AND BASES}

\subsubsection{Testability}

The electrical support system contains standard commercial components. System design does not necessitate unique design requirements for testability.

\subsubsection{Technical Safety Requirement-Required Surveillances}


The electrical support system is non-SC, and will not be subject to Technical Safety Requirement (TSR)-required surveillances.

\subsubsection{Non-Technical Safety Requirement Inspections, and Testing}

The electrical support system contains standard commercial components. These do not require special non-TSR inspections, and testing that will necessitate unique design requirements. A test program for the system will be developed using manufacturer's recommendations as guidance.

\subsubsection{Maintenance}

The electrical support system maintenance activities, to comply with the manufacturer's recommendations, will be developed as needed.

\subsection{OTHER REQUIREMENTS AND BASES}

\subsubsection{Security, and Special Nuclear Material Protection}

Security, and special nuclear material (SNM) protection requirements for the electrical power system design will be developed if required.

\subsubsection{Special Installation Requirements}

The electrical support system contains standard commercial components. These will be installed according to the manufacturer's instructions. Minimum required working clearances would be in accordance with NEC standards and National Electric Safety Code.

\subsubsection{Reliability, Availability, and Preferred Failure Modes}

There are no unique requirements for system reliability or availability. The electrical support system mission requirements are contained in Section 3.1.1.3. For lighting subsystem, these include the use of preferred, and alternate utility supplies, the standby, and emergency power subsystems, and UPS. The electrical support system is non-SC, and therefore does not have a preferred failure mode. The reliability for the cathodic protection, and heat tracing subsystems will depend on the reliability of the utility supplies.

\subsubsection{Quality Assurance}

The electrical support system is non-SC, and is not subject to the requirements of the quality assurance program described in Quality Assurance Requirements, and Description (DOE 2004).

\subsubsection{Miscellaneous}

No system requirements have been identified for this section. 


\section{SYSTEM DESCRIPTION}

\subsection{CONFIGURATION INFORMATION}

\subsubsection{Description of System, Subsystems, and Major Components}

The electrical support system is comprised of six subsystems involved in ensuring that the electrical power system, and facility process for the repository are operable at all times as designed. Although they are grouped together as one support system, each one of these subsystems has its own specific function in providing the electrical power required for the operation of the facility.

The electrical support system components are capable of performing their intended function for their intended lifetime in the radiation field they are located. This capability is provided through shielding or hardening of the equipment or planned replacement of components, if needed. The electrical support system includes the following subsystems:

- Lighting

- Grounding

- Lightning protection

- Cathodic protection

- Heat traceing

- Cable raceway

\subsubsection{Description of Lighting Subsystem}

The lighting subsystem designed for the repository facilities is a reliable system. It provides comfort to the users, especially in the area of CCTV, laboratory, and control room. The lighting subsystem is designed to be at least consistent with the illumination requirements of PDC [4.3.1.2.1, and 4.3.1.2.2], IESNA Lighting Handbook-2000, $9^{\text {th }}$ Edition (Rea, M. S. 2000), ANSI/IESNA RP-22-96 1996, and the NFPA 70-2002 [3.1.1.3.1.1, and 3.1.1.3.1.2].

The lighting subsystem for the repository is subdivided into normal lighting, essential lighting, and emergency lighting. The lighting subsystem uses 480/277 VAC or 208/120 VAC power.

Normal lighting is provided in areas such as roadways, parking areas, general building areas, and other general outdoor areas where extended loss of light does not impact personnel safety or production. Normal lighting is powered from either of the two off-site utility sources: $230 \mathrm{kV}$, the preferred source, or $138 \mathrm{kV}$, the alternate source. As a result, outage of both utility sources will cause the normal lighting subsystem to be out of service. However, these outages will not have any adverse impact where normal lighting is provided.

Essential lighting is provided in areas where repository operations, and processes are required to maintain sustained operation that cannot tolerate long periods of loss of light due to outages of both off-site utility sources. Therefore, essential lighting is powered from either of the two offsite utility sources, the $230 \mathrm{kV}$ source as the preferred source, or the $138 \mathrm{kV}$ as the alternate 
source, and from backup standby diesel generators. This configuration will prevent long periods of loss of light where essential lighting is required due to outages of both off-site utility sources.

Emergency lighting includes egress lighting. Emergency lighting is provided where extended loss of light cannot be tolerated due to personnel safety, and for sustained operations in areas such as the Central Control Center Facility (CCCF), CCTV, local control panels, monitors, and waste package process facilities due to total loss of off-site power. Upon loss of off-site $230 \mathrm{kV}$, and $138 \mathrm{kV}$ power sources, the emergency lighting subsystem receives its 208/120 VAC power from $4.16 \mathrm{kV}$ emergency diesel generators system for the lighting area that can tolerate momentary loss of light, and a UPS system for the lighting area that cannot tolerate momentary loss of light. The UPS system provides power for emergency lighting in CCCF, and facility control room areas, critical CCTV areas, $4.16 \mathrm{kV}$ switchgear facility, and radiation monitoring areas that are needed during emergency operating conditions. Egress lighting is provided in stairways, exit routes, fire alarm stations, stations in ventilation shafts used for emergency egress, subsurface ramps, and for exit signs for surface facilities, and subsurface tunnels. Egress lighting is powered by self-contained dry battery packs/inverters within each fixture that turns light on upon loss of $120 \mathrm{VAC}$. Therefore, egress lighting is not connected to emergency bus.

The lighting subsystem design is in its preliminary stage. The design information for the lighting subsystem will be updated in future revisions as the design evolves.

\subsubsection{Description of Grounding Subsystem}

The ground grid system is comprised of a network of buried, embedded, or exposed bare copper cables with grounding rods that are interconnected to form a grid to which all electrical equipment, and system ground, building, and structure steel, buried or exposed, are connected. The ground grid is located in the $230 \mathrm{kV} / 138 \mathrm{kV}$ switchyard.

The ground grid is designed per the requirements of the IEEE Standard 80-2000 to obtain safe touch, and step potentials. The ground conductor is sized to carry maximum system ground fault current in accordance with NFPA 70-2002. The power system grounding is based on the following criteria [PDC 4.3.1.4.7]:

- $12.47 \mathrm{kV}$ system: This system shall be grounded through a resistor to limit damaging ground fault current to a value adequate for relay operation (low resistance grounding)

- $4.16 \mathrm{kV}$ system: This system shall be grounded through a resistor to limit damaging ground fault current to a value adequate for relay operation (low resistance grounding)

- $480 \mathrm{Y} / 277 \mathrm{~V}$ system: The system neutral point shall be solidly grounded to the ground grid

- $208 \mathrm{Y} / 120 \mathrm{~V}$ (including UPS): The system neutral point shall be solidly grounded to the ground grid 
- 125 VDC system: Ungrounded

- DC return rail tracks: Ungrounded.

Equipment is grounded per the requirements of the IEEE Standard 142-1991, and NFPA 702002. Equipment grounding connects all non-current carrying parts of all electrical equipment, metallic structures, and electrical raceways to the ground grid [3.1.1.3.2.3]. Equipment grounding is provided to equalize the ground potential between the equipment, and the ground grid. The equipment ground conductor can be a bare or insulated conductor or bus bar, metal raceway, metal cable sheath, or any combination of the above.

The instrument grounding system consists of insulated ground busses interconnected with insulated cables to form a radial system. The instrument grounding, although it also connects to the overall grounding subsystem, is kept separate, and insulated, until it connects to the grounding subsystem at one specific point to eliminate electrical noise problems on the power supply lines for instrument, and monitoring equipment, see Figure 2-1. All instrumentation equipment such as analog, and digital equipment cabinets, computer cabinets, and annunciator cabinets are supplied with a signal grounding bus insulated from the metal cabinet, and the cabinet grounding bus. Separate analog, and digital grounds are maintained up to the main instrument signal grounding bus. The main instrument signal ground bus is provided with two separate groupings of ground connections: analog signal ground, and digital signal ground. The isolated ground bus is connected to the ground grid electrodes through a test switch link [3.1.1.3.2.4]. See Figure 2-1.

The perimeter fencing within the ground grid area is grounded. Fence posts within the ground grid area are grounded at alternate intermediate posts. Under-ground duct banks are embedded the entire length of the duct banks, located as close as possible to the top center of the duct bank. Duct bank ground conductors are connected to all other ground conductors in manholes, and hand-holes.

All railway tracks within the facility area are connected to the ground grid. Rail splice jumpers are required for ground continuity. The first rail sections on each rail outside the ground grid area have insulating joints on both ends. Please note that DC return rail tracks shall not be grounded.

Buildings are grounded by connecting every other building column directly to the ground grid. Ground connection to the column is made by exothermic process above the finished floor elevation. All other exposed or accessible indoor grounding connections are made with compression connectors.

The overall grounding subsystem is a single grounding network, which interconnects all the repository facilities: North Portal, South Portal, North Construction Portal, balance of plant, ventilation system areas, subsurface facilities. The ground grid connects to the rest of the surface, and subsurface repository grounding conductors, and grounding rods. 
At present, the ground grid design is in a preliminary stage. The detailed design information will be updated in future revisions as the design evolves.

\subsubsection{Description of Lightning Protection Subsystem}

The lightning protection subsystem is designed per the requirements of NFPA Standard 7802001, and UL 96A-2001 to provide a reliable designated low resistance path for carrying lightning current to the ground harmlessly, and thereby protect electrical equipment, buildings, and elevated structures against damages caused by lightning strikes, see Figure 2-1.

A lightning protection subsystem is made up of following components.

Air Terminals: Inconspicuous slender rods installed on top of the roof at regular intervals.

Conductors: Aluminum or copper cables that interconnect the air terminals, and the other system components.

Ground Terminations: Metal rods driven into the earth to guide the lightning current harmlessly to ground.

Surge Arrestors, and Suppressors: Devices that are installed in conjunction with a lightning protection system to protect electrical wiring, and electronic systems, and equipment.

Lightning protection to buildings, and other elevated outdoor structures is provided by installing strike termination devices such as air terminals or vertical rods located above the structures, and a conductor system connecting them to ground rods that are, in turn, connected to the ground grid terminals per the installation requirements of the UL 96A-2001. The down conductors serve as the low impedance path to ground to allow lightning strikes to discharge to earth with minimal damage to facilities.

All outdoor metal tanks, and metal silos are bonded to the ground grid through their foundation reinforcement bars.

Surge protection for the electrical system, and equipment is essentially the same as the lightning protection system. The proper operation of the surge protective devices depends on limiting the low surge impedance path to ground for impulse-type over-voltages occurring on the power system.

At this time, the lightning protection design is in its preliminary design stage. The design information for the lightning protection will be updated in future revisions as the design evolves.

\subsubsection{Description of Cathodic Protection Subsystem}

Cathodic protection subsystem is designed to control external corrosion on the metallic pipes, tanks, and structures buried, or in contact with ground per the requirements of NACE Std. RP0169-2002 to obtain a reliable system. The system consists of components such as rectifiers, 
anodes, anode loop cables, terminal, and junction boxes, test stations, reference electrodes, and some bonding jumpers. See Figure 2-2.

The impressed current type cathodic protection subsystem mitigates the effects of corrosion by forcing all areas of a metallic structure to become a cathode. This is accomplished by the flow of current from the anode ground bed to the pipeline or metallic structure, and back to the negative terminal of the rectifier. The rectifier has adjustable voltage taps for adjustment of the negative polarization of the pipe. The potential requirement for inhibiting corrosion is a negative potential as measured between the structure, and a saturated copper-copper sulfate reference electrode in contact with the electrolyte.

The impressed current type cathodic protection subsystem utilizes DC current provided by a rectifier powered from the site normal $120 \mathrm{VAC}$ or $480 \mathrm{VAC}$ power system. Impressed current anodes can be of materials such as graphite, high-silicon cast iron, lead-silver alloy, precious metals, or steel. These anodes are connected with an insulated cable, either individually or in groups, to the positive terminal of a DC source, such as a rectifier. The pipeline or structure is connected to the negative terminal of the DC source.

The environmental conditions, and the physical layout of the pipes, and other structures determine the type, location, spacing, and total number of anodes required. Based on the calculation, anodes are spaced at optimum distances from each other, and from the protected pipes or structures. Anodes are installed vertically or horizontally adjacent to the pipes, and other structures, and interconnected by use of an anode header cable, and an anode loop cable. Anode shunt terminal boxes are provided near underground tanks to permit ampere output testing of each anode. Anode junction boxes are used elsewhere to permit continuity testing of the anode header, and anode loop cables.

Pipe or structure test stations are provided to permit testing of both protected, and non-protected underground pipes, and structures. For pipes, the test stations are located strategically along the pipelines, and installed where protected pipes cross non-protected pipes, and also at valve pits. Each test station includes a minimum of one permanent underground reference electrode located below the pipeline. Leads from the reference electrode, and leads that have been exothermically welded to the pipes, and other structures are extended to terminals within the test station.

Bonding jumpers are provided to interconnect all underground metallic piping, and other metallic structures to eliminate stray currents. Potentials are measured periodically, using these test stations, to determine the effectiveness of the cathodic protection system.

At this time, the cathodic protection design is in its conceptual stage. The design information for the cathodic protection subsystem will be updated in future revisions as the design evolves.

\subsubsection{Description of Heat Tracing Subsystem}

The heat tracing subsystem is designed to keep liquid filled pipes, instrument sensing lines, and tanks operable for an outdoor temperature range as defined in the PDC section 6.1.1.5, ambient temperature. The heat tracing subsystem is designed per the requirements of the IEEE 515-1997, and NFPA 70-2002 to obtain a reliable system. The heat tracing subsystem is made up of four 
major parts: heating elements, a temperature sensing unit, a temperature controller, and an electrical circuit supply.

Heating elements are used to keep the liquid above its freezing point. Two types of heating elements are used. First, there is the heat tracing cable element used for pipes, and small tanks, and second, the heater pads or heating panels used for large tanks. The heat tracing cables are self-limiting, power limiting, constant wattage, flexible, series resistance cables. The heater cables are secured to the piping with polyester fiber or glass cloth adhesive tape, and bent to conform to the contour of the pipe or flange. Heating pads are used for large tanks where parallel heat tracing cables are unable to maintain sufficient heating due to the large surface area of the tank.

The temperature-sensing units used are thermostats, and resistance temperature detectors. Ambient sensing thermostats are used for water utilities, and noncombustible liquid chemicals. Resistance temperature detectors are used for diesel fuel lines for winterizing, and are placed against the pipe wall to sense the temperature. Dedicated temperature controllers are used for heat tracing. Temperature controllers control the operation of the heating element.

The electrical supply for the heat tracing subsystem is 208/120 VAC, 3-phase, 4-wire service. The heat tracing circuitry is divided into zones, and protected by circuit breakers, and contactors for separate system isolation. In heat tracing circuit, ground leakage protection is employed to provide both local, and remote indication of a ground fault. The detection will enable prevention of larger faults.

At this time, the heat trace design is in its conceptual stage. The design information for the heat trace system will be updated in future revisions as the design evolves.

\subsubsection{Description of Cable Raceway Subsystem}

The cable raceway subsystem designed for the repository is a reliable, and robust system. The cable raceway for 600 volts nominal or less is designed per the requirements of NFPA 70-2002, Chapter 3, and PDC. The cable raceway for the medium voltage system is designed using electrical criteria from PDC, and industry standards such as IEEE, NEMA, and other applicable industry standards. The cable raceway supports for the emergency power system is designed per the requirements of Section 3.2.5.2.1.

The cable raceway subsystems are divided into two major classes: exposed system, and embedded system. Exposed system utilizes cable tray or conduit, arranged in a main distribution pattern branching out to serve individual equipment or device. Embedded raceway system consists of conduit embedded in building floors, including trench, walls, and underground duct banks with manholes, and hand-holes. In order to maintain separation, and sustain orderly installation, quite often cable trays are installed inside the manholes.

The cable raceway subsystems are physically separated in accordance with the function, and voltage class of the cables, i.e., $15 \mathrm{kV}$ cables, $5 \mathrm{kV}$ cables, AC, and DC $600 \mathrm{~V}$ cables, $120 \mathrm{VAC}$, 
and $125 \mathrm{~V} \mathrm{DC}$ cables, emergency control cables, low level analog signals, digital data, and fire detection cables as well as specialty cable, or Fiber Optics.

In areas where raceway systems require stacked trays, the cables with higher voltage level occupy the highest position in the stack. Control cables are located below low voltage power trays, and low voltage analog, digital, and fiber optic cables are located below control cable trays. Tray systems for each voltage level application are installed from top to bottom order as shown below:

- $15 \mathrm{kV}$ cables

- $5 \mathrm{kV}$ cables

- Low voltage power AC, and DC-600 V cables

- High-level control signal or discrete on/off control cables (120 VAC, 125 VDC)

- Instrumentation cables (that is, low-level analog, and digital signal.)

- Communications cables.

The electrical support is a non-ITS system. However, for the selected critical emergency redundant loads " $\mathrm{A}$ ", and " $\mathrm{B}$ ", cable raceways from the emergency power systems $\mathrm{A}$, and $\mathrm{B}$ are separated from each other, and routed via separate fire zones in accordance with the principles defined in NFPA 70-2002, Article 700.9. This configuration will prevent simultaneous loss of redundant emergency loads due to a fire in a fire zone, or other hazards such as flooding, icing, and vandalism. Cables associated with each emergency power system load group are run in separate conduits, cable trays, or ducts.

To date, detailed equipment layout is being developed to support the design of the Fuel Handling, and Canister Handling Facilities. The conceptual raceway system design for the subsurface Motor Control Centers, and Load Centers including manholes/raiser transition is on the verge of completion. Further, the conceptual raceway system design for the subsurface exhaust fans are in the process of completion. The design information for the raceway system will be updated in future revisions as the design evolves.

\subsubsection{Electrical Support System Boundaries, and Interfaces}

The electrical support system boundaries, and interfaces include those breakers that route power to various plant systems, except for grounding subsystem. The grounding subsystem provides interface to the electric power supply by providing a low resistance path to the grounding subsystem.

\subsubsection{Lighting Subsystem Boundaries, and Interfaces}

The lighting subsystem boundary starts at the switchyard in the North Portal, including the outdoor lighting for the fenced perimeter, and parking areas. The lighting boundary extends to the outlying areas in the South Portal, which includes the construction area, the ventilation shafts area, and the railroad facility area. 


\subsubsection{Grounding Subsystem Boundaries, and Interfaces}

As with most of the electrical support systems, the grounding subsystem interfaces start at the switchyard, and terminate at the outermost location of the repository where electrical power is connected.

\subsubsection{Lightning Protection Subsystem Boundaries, and Interfaces}

The lightning protection subsystem boundary starts at the switchyard, and terminates at the farthest elevated structures of the repository that requires protection from lightning strikes.

\subsubsection{Cathodic Protection Subsystem Boundaries, and Interfaces}

The cathodic protection subsystem boundary starts at the switchyard, and terminates at the outermost structure of the repository where metallic equipment or structure is in contact with the ground.

\subsubsection{Heat Tracing Subsystem Boundaries, and Interfaces}

Heat trace system boundary starts from the Dry Transfer Facility where any of the process piping extends outdoors, and requires protection from freezing temperatures.

\subsubsection{Cable Raceway Subsystem Boundaries, and Interfaces}

The cable raceway subsystem boundary starts at the switchyard, and terminates at the farthest location of the repository to service all loads, instrumentation, and control devices that requires electrical cables.

\subsubsection{Physical Locations, and Layout}

The ground grid is located inside the $138-\mathrm{kV} / 230 \mathrm{kV}$ switchyard located at the southwest corner of the North Portal facility.

No other physical locations or layout description have been identified at this time.

\subsubsection{Principles of Operation}

\subsubsection{Lighting}

The lighting subsystem provides the required illumination levels in various areas of the repository through operation of light switches, breakers, and other various sensing devices (photo, motion, etc.). The system requires a $\pm 10 \%$ of the nominal voltage rating to maintain acceptable illumination levels.

\subsubsection{Grounding}


During phase to ground fault, the grounding subsystem provides low resistance ground return path to facility ground grid to dissipate fault currents into the earth without exceeding any operating, and equipment limits, and assure that personnel in the vicinity of grounded facility is not exposed to the danger of critical electric shock by keeping touch, and step potentials to safe levels.

\subsubsection{Lightning Protection}

The lightning protection subsystem operates by intercepting lightning strikes at rods installed on building roofs, and provides a designated ground path for the lightning current to dissipate to the ground grid, and thereby, protect electrical equipment, buildings, and elevated structures against damages caused by lightning strikes.

\subsubsection{Cathodic Protection}

The output of each cathodic protection rectifier is connected across the anode ground bed, and the underground pipes or other structures to be protected. The cathodic protection subsystem operates by allowing flow of current from the anode ground bed to the pipeline or metallic structure, and then back to the negative terminal of the rectifier by maintaining a negative potential between the pipe or structure, and a saturated copper-copper sulfate reference electrode in contact with the electrolyte.

\subsubsection{Heat Tracing}

The heat trace system provides freeze protection for liquid-filled piping, instrument sensing lines, and small tanks that would be susceptible to freezing during the winter months by using a self-limiting heating cable, or electrical heating element, around the pipe or sensing line. As the heating cable is self-limiting, the heat output regulates temperature to ambient conditions at each point of the cable. As a result, it never overheats or burns out-even when overlapped on itself. In snow, and icy water, the self-limiting heating cable operates at full power. As the snow melts, and the water drains away, self-limiting heating cable self-regulates to half power while it dries. As it gets warmer, the self-limiting heating cable gradually reduces its heat output. Tank heating pads are used when high wattage density is required. These tank-heating pads provide heat to selected areas on the tank. The heat is then distributed through convection in the fluid. The tank heating pads have a constant power output, and use sealed, self-resetting thermostat to regulate liquid temperature.

\subsubsection{Cable Raceway}

The cable raceway subsystem is a passive system. It is primarily used to provide physical protection, and routing of electrical power, and instrument cables routed from the power supply to the electrical loads, and of cables interconnecting control, and monitoring equipment.

\subsubsection{System, and Subsystem Reliability Features}


The provisions of reliability requirements are based on the final system configuration, and hardware information. A review of these considerations will establish reliability requirements for this section. No reliability requirements have been identified at this time.

\subsubsection{System, and Subsystem Control Features}

The detailed information for the control logic diagrams, indications, alarm, and control features for the electric support systems will be updated in future revisions as the design evolves.

\subsection{OPERATIONS}

As the repository design matures, the good operations practices for the electrical support systems will be identified in this section.

\subsubsection{Initial Configuration (Pre-startup)}

The requirement of pre-startup requirements is based on the final system configuration. A review of these considerations will establish the pre-startup requirements. No pre-startup requirements have been identified at this time.

\subsubsection{System, and Subsystem Startup}

The requirement of startup requirements is based on the final system configuration. A review of these considerations will establish startup requirements. No startup requirements have been identified at this time.

\subsubsection{Normal Operations}

The description of normal operating mode for the electrical support systems will be based on the final system configuration. A review of these considerations will establish normal operating mode.

\subsubsection{Off-Normal Operations}

The description of off-normal operating mode for the electrical support systems will be based on the final system configuration. A review of these considerations will establish off-normal operating mode.

\subsubsection{System, and Subsystem Shutdown}

The description of system, and subsystem shutdown for the electrical support systems is based on the final system configuration. A review of these considerations will establish system, and subsystem shutdown operating mode.

\subsubsection{Safety Management Program, and Administrative Controls}


As the repository design matures, the safety management program, and administrative control that apply to the electrical support systems will be identified in this section.

\subsection{TESTING, AND MAINTENANCE}

As the repository design matures, separate testing, and maintenance programs, and temporary configurations will be identified in this section.

\subsubsection{Temporary Configuration}

Situations under which temporary configurations are used during surveillance or maintenance are based on the final system configuration. A review of these considerations will establish temporary configurations requirements. No temporary configurations requirements have been identified at this time.

\subsubsection{TSR Required Surveillances}

These requirements will be based on the final system configuration, and its contribution to preclosure, and post-closure performance objectives. A review of these considerations will establish the set of necessary surveillance, inspection, and testing requirements. No surveillance, inspection, and testing requirements have been identified at this time. The above requirements will be determined as the design process matures.

\subsubsection{Non TSR Surveillances, Inspections, and Testing}

Procedures will be developed to define, and describe surveillances, inspections, and testing requirements. The procedures will be based on manufacturers recommendations, and final system configuration.

\subsubsection{Maintenance}

Maintenance requirements for the electrical support systems include the development of preventive maintenance, and post maintenance testing processes, and any post modification testing programs. The maintenance program for the electrical support systems will be developed as part of the repository maintenance program. 


\section{REFERENCES}

\subsection{DOCUMENTS CITED}

BSC (Bechtel SAIC Company) 2004. Safety Classification of SSCs, and Barrier. CAL-MGRRL-000001, Rev. 00B. Las Vegas, Nevada: Bechtel SAIC Company. ACC:

DOC.20030929.0014 [DIRS 169971]

BSC (Bechtel SAIC Company) 2003. Q-List. TDR-MGR-RL-000005 REV 00. Las Vegas, Nevada: Bechtel SAIC Company. ACC: DOC.20030930.0002. [DIRS 165179]

BSC (Bechtel SAIC Company) 2003. Preliminary Nuclear Safety Design Bases for License Application. TDR-MGR-RL-000006 REV 00. Las Vegas, Nevada: Bechtel SAIC Company. ACC: DOC.20030930.0008. [DIRS 165182]

BSC (Bechtel SAIC Company) 2004. Preliminary Hazards Analysis for License Application. 000-30R-HPYK-00100-000-00A. Las Vegas, Nevada: Bechtel SAIC Company. ACC: ENG.20040610.0002. [DIRS 167313]

BSC (Bechtel SAIC Company) 2004. Site Fire Hazards Analysis. 000-30R-PF00-00100-00000A. Las Vegas, Nevada: Bechtel SAIC Company. ACC: ENG.20040305.0014. [DIRS 168149]

BSC (Bechtel SAIC Company) 2004. Subsurface Repository Fire Hazard Analysis. 800-30RPF00-00100-000-00A. Las Vegas, Nevada: Bechtel SAIC Company. ACC:

ENG.20040303.0043. [DIRS 168726]

Doraswamy, N. 2004. "Preliminary Draft Input Version of Project Design Criteria Document." Interoffice memorandum from N. Doraswamy (BSC) to Distribution, May 26, 2004, 0526041747, with attachment. ACC: MOL.20040526.0027. [DIRS 169548] TBV -5850

Siddoway, D.W. 2003. Project Functional, and Operational Requirements. TDR-MGR-ME000003 REV 01. Las Vegas, Nevada: Bechtel SAIC Company. ACC: ENG.20030630.0001 [DIRS 163904]

Canori, G.F., and Leitner, M.M. 2003. Project Requirements Document. TER-MGR-MD000001 REV 02. Las Vegas, Nevada: Bechtel SAIC Company. ACC: DOC.20031222.0006. [DIRS 166275]

\subsection{CODES, STANDARDS, REGULATIONS, AND PROCEDURES}

10 CFR 63. Energy: Disposal of High-Level Radioactive Wastes in a Geologic Repository at Yucca Mountain, Nevada. Readily available. [DIRS 156605] 
DOE (U.S. Department of Energy) 2004. Quality Assurance Requirements, and Description. DOE/RW-0333P, Rev. 14. Washington, D.C.: U.S. Department of Energy, Office of Civilian Radioactive Waste Management. ACC: DOC.20030422.0003. [DIRS 162903]

DOE-STD-3024-98. 1998. Content of System Design Descriptions. Washington, D.C.: U.S. Department of Energy. TIC: 254659. Verified. [DIRS164472]

'NFPA 70. 2002. National Electrical Code. 2002 Edition. Quincy, Massachusetts: National Fire Protection Association. TIC: 252084. [DIRS 157764]

IEEE Std. 80-2000, IEEE Guide for Safety in AC Substation Grounding. New York, New York: Institute of Electrical, and Electronics Engineers. TIC: 254157. [DIRS 164256]

IEEE Std. 81-1983. IEEE Guide for Measuring Earth Resistivity, Ground Impedance, and Earth Surface Potentials of a Ground System. New York, New York: Institute of Electrical, and Electronics Engineers. TIC: 232605. [DIRS 102325]

IEEE Std. 142-1991, IEEE Recommended Practice for Grounding of Industrial, and Commercial Power Systems. New York, New York: Institute of Electrical, and Electronics Engineers. TIC: 235220. [DIRS 122245]

IEEE Std. 515-1997. IEEE Standard for the Testing, Design, Installation, and Maintenance of Electrical Resistance Heat Tracing for Industrial Applications. New York, New York: Institute of Electrical and Electronics Engineers. TIC: 256044. [DIRS 169569]

NFPA 780-2001, Standard for the Installation of Lightning Protection Systems. 2000 Edition. Quincy, Massachusetts: National Fire Protection Agency. TIC: 252748. [DIRS 158854]

Rea, M.S., Ed. 2000. IESNA Lighting Handbook, Reference \& Application. $9^{\text {th }}$ Edition. New York, New York: Illuminating Engineering Society of North America. TIC: 254894. [DIRS $165131]$

NACE Standard RP0169-2002. Standard Recommended Practice, Control of External Corrosion on Underground or Submerged Metallic Piping Systems. Houston, Texas: National Association of Corrosion Engineers. TIC: 254895. [DIRS 165132]

ANSI/IESNA RP-22-96. 1996. IESNA Recommended Practice for Tunnel Lighting. New York, New York: Illuminating Engineering Society of North America. TIC: 255084. [DIRS 166693]

UL 96A. 2001. Installation Requirements for Lightning Protection Systems. $11^{\text {th }}$ Edition. Northbrook, Illinois: Underwriters Laboratories. TIC: 255223. [DIRS 166768]

LP-3.26Q-BSC, Rev.1/ICN 4, System Description Documents (DIRS 167662) 
Electrical Support SDD

\subsection{DATA TRACKING NUMBER}

No source data are cited in this document.

\subsection{SOFTWARE CODES}

No software codes are cited in this document. 
Electrical Support SDD

APPENDIX A

\section{GLOSSARY}




\begin{abstract}
APPENDIX A
GLOSSARY

Basis

Statements that refer to design requirements for SSCs, and identify why the requirement exists, why it is specified in a particular manner, and why a specified value is used. The design bases provide information that identifies the specific functions performed by the SSCs of a facility, and the specified range of values chosen for controlling the parameters that are the referenced boundaries for the design of the SSCs.
\end{abstract}

Function

Requirement

Step Potential

Touch Potential

Off-Normal
A function is the statement of the purpose of a system or component.

A specification of what the design solution must do. Requirement statements should also include a statement of how well the specification is to be achieved so as to permit verification. In some cases, there are several different criteria for measuring the success of the achievement of the specification, and these would be listed as performance acceptance criteria.

The difference in surface potential experienced by a person bridging a distance of 1 meter with the feet without contacting any grounded object.

The potential difference between the ground potential rise, and the surface potential at the point where a person is standing while at the same time having a hand in contact with a grounded structure.

"Off-Normal" is a term used to define an occurrence of an event or condition outside the bounds of routine operations but within the range of analyzed conditions for theSSC. 
Electrical Support SDD

APPENDIX B

LIST OF KEY SYSTEM CHARTS, DIAGRAMS, DRAWINGS, AND LISTS 
Electrical Support SDD

APPENDIX B

LIST OF KEY SYSTEM CHARTS, DIAGRAMS, DRAWINGS, AND LISTS

None at this time but will be developed later. 
Electrical Support SDD

APPENDIX C

LIST OF SYSTEM PROCEDURES 


\section{APPENDIX C \\ LIST OF SYSTEM PROCEDURES}

System procedures have not yet been developed. 